\title{
El Estado en momentos de crisis: Redefinición del papel del Estado 1948-1960
}

\author{
Alfonso Goitia
}

\section{Introducción}

El Estado en El Salvador ha jugado un papel importante en el desarrollo del proceso de acumulación de capital, a su vez ha logrado articular todo un conjunto de mecanismos para resolver los momentos de crisis del proceso de acumulación y ha tratado de establecer los instrumentos necesarios para la legitimación y el concenso social en torno a un proyecto político-económico determinado.

Estos elementos nos llevan a la necesidad de establecer tres roles fundamentales del Estado, el primero, mediante el cual crea los mecanismos adecuados a fin de garantizar la lógica de la acumulación y por lo tanto a fortalecer la orientación esencial del modelo económico; el segundo, relacionado a la implementación de medidas, instrumentos o acciones vinculadas a la efectividad y eficiencia del Estado para llevar a cabo los objetivos generales y específicos que consideran en cada momento; y el tercer rol esta en función de propiciar el concenso social en torno a un proyecto político-económico determinado, que debe pasar a su vez por la conformación de las condiciones adecuadas de bienestar para la población o a través de otras acciones de carácter político-ideológico que permitan el concenso.

Se trata por lo tanto, de analizar y estudiar un monento importante en el desarrollo del Estado salvadoreño en el marco de su acción económica y social, además de considerar su papel en un contexto de crisis y de redefinición ante la crisis.

Este momento está ubicado en 1948, situación de crisis política y de una readecuación del modelo económico prevaleciente tendiente a dinamizar la lógica de acumulación del capital. Ciertamente es un momento de conflicto político-social y de crisis del Estado, pero al mismo tiempo se presenta la necesidad de establecer los mecanismos necesarios al 
proceso de industrialización y de lograr el concenso social en torno a un proyecto industrializante en lo económico con un Estado benefactor en lo social.

El 14 de Diciembre de 1948 un golpe de Estado depuso al Presidente Castaneda Castro y se instaló un Consejo de Gobierno Revolucionario integrado por el Teniente Coronel Manuel de J. Córdova, Mayor Oscar Osorio A. Bolaños, Dr. Humberto Costa y Dr. Infieri Reynaldo Galindo Pohl.

Este acontecimiento político marcará importantes cambiós en el proceso de acumulación de capital, pero así mismo significará una redefinición del Estado con el objeto de asumir un rol más relevante en la actividad económica y en la orientación industrializante de ésta. "El nuevo gobierno establece una politica "revolucionaria" que moderniza el edificio juridico al poner las bases legales de un capitalismo "moderno," y tomar las medidas de política económica tendientes a permitir un proceso de acumulación de capital en el pais". 1

Entre 1944 y 1948 el ambiente político en El Salvador se habia convulsionado, los golpes de Estado, algunos intentos de golpes y los sucesivos gobiernos militares no habian resuelto la inestabilidad politica-social existente. Ciertamente las huelgas y el descontento popular se habia exacerbado durante este periodo. En este contexto "el Ejército en su conjunto se encuentra en un equilibrio inestable". El Estado asímismo se encuentra en crisis. En el ámbito internacional se presentará en estos años condiciones relativamente positivas para una reorientación de la economia y del rol del Estado. La coyuntura favorable de los precios del café, las concepciones nacionalistas-industrializantes "que venian abriendose campo y que se concreta en América Latina con la creación de la CEPAL en el año de 1948," las experiencias industrializantes en América Latina, asi como los cambios que experimenta el capitalismo de post-guerra con su tendencia hacia la internacionalización del capital fundamentado en la industria, son algunos factores a considerar en el proceso de redefinición del Estado en El Salvador.

Al interior de la economia salvadoreña, el relativo desarrollo industrial alcanzado en los años anteriores a 1948 y las limitaciones para la expansión de ésta en mayor escala, volvían necesario la "modificación de las pautas seguidas en materia de inversión por los agro-exportadores. Por un lado debia transformarse su predilección por las formas tradicionales que habían observado durante casi toda su historia y se les debia de demostrar que no existia ningun tipo de riesgos, tales como pérdidas de capital o graves inmovilizaciones de capital liquido, en las inversiones en nuevas industrias y en la ampliación de las ya existentes". 2

En su conjunto la presencia de estos factores económicos, políticos, 
sociales e internacionales propiciarian el ambiente necesario para las readecuaciones del proceso de acumulación de capital y del nuevo papel del Estado en El Salvador.

\section{Las potencionalldades de la industrlalización y el papel del Estado}

El Estado salvadoreño había ido adquiriendo una relativa importancia en las actividades económicas desde los ańos '30, pero esencialmente respondía a la dinámica agro-exportadora y a los problemas que podría enfrentar esta actividad en relación al comercio internacional.

"Para 1948, la actividad estatal estaba determinada por su dependencia casi absoluta de las políticas económicas del sector agro-exportador y por un marco juridico liberal -de tinales del siglo anterior- que se volvía un obstáculo para el crecimiento de la libre empresa y para encontrar solución a los graves problemas socio-económicos del país". ${ }^{3}$

Esta situación hacia necesario ciertos cambios que si bien no afectarian la estructura socio-económica del país, permitirían nuevas condiciones para el desarrollo empresarial.

La industrialización se convertia asi, en una alternativa viable a las limitaciones y dificultades que la economia experimentaba en relación a su carácter esencialmente agro-exportador. A su vez, ésta podría propiciar una expansión de la economía. A fin de dinamizar otras actividades, se presentaba también las posibilidades de una mayor diversificación de la economía que permitiría superar la dependencia externa y en general lograr el desarrollo económico y social.

Esta visión modernizante de la economía estaba presente en los grupos industrializantes; habrá que considerar ahora si existian las condiciones necesarias para una re-orientación de la economia y como el Estado asume este papel promotor de la industrialización en el proceso de acumulación de capital.

\subsection{Factores favorables a la Industrlalización}

Se ha señalado que el esquema agro-exportador proporcionaba al mismo tiempo elementos industrializantes y anti-industrializantes. Es decir, "la economia de exportación genera en su desarrollo un conjunto de condiciones que favorecen, que impulsan la industrialización; pero, su propia naturaleza lo hace producir simultaneamente un efecto contrario: un conjunto de condiciones que van a limitar la realización del proceso que ella impulsa". 4

De 1945 a 1956 el valor de las exportaciones habia crecido más de 5 veces de 53.3 millones de colones a 281.8 millones de colones. Las exportaciones de café representaban en este periodo alrededor del $84 \%$ 
del total de exportaciones, su valor exportado habia también aumentado más de 4 veces y sus precios en el mercado internacional habian crecido hasta $38.3 \%$ en 1954. Esta situación altamenten favorable para el grupo exportador le significó ingresos reales muy grandes.

"La favorable relación de precios de intercambio le procuró al gnupo exportador un ingreso real durante estos seis años (1945-1950) que pasó de 66.2 millones de colones en 1945 a 171 millones de colones en1950, llegando a representar en este último año, el $20.2 \%$ del valor total del producto interno bruto producido por la economía de ese año". 5

Este decir, que durante este periodo existe un proceso de acumulación de capital importante en el grupo agro-exportador especialmente el orientado a la producción y exportación de café, el problema radicaba en cómo incentivar o posibilitar la reorientación de este capital hacia la actividad industrial, cómo hacer atractiva la inversión en la industria.

Cuadro No. 1

Valor de las exportaciones y precios del café 1945-1956

(Millones de colones y dólares por quintal)

\begin{tabular}{|c|c|c|c|c|}
\hline Año & Total & Café & Otras & Precios del café \\
\hline 1945 & 53.3 & 46.7 & 6.6 & 15.91 \\
\hline 1946 & 65.4 & 51.6 & 13.8 & \\
\hline 1947 & 100.2 & 84.3 & 15.9 & \\
\hline 1948 & 114.0 & 90.4 & 23.6 & 29.52 \\
\hline 1949 & 137.4 & 119.0 & 18.4 & \\
\hline 1950 & 173.8 & 154.5 & 19.2 & 50.91 \\
\hline 1951 & 213.8 & 190.1 & 23.7 & 55.51 \\
\hline 1952 & 220.8 & 194.0 & 24.7 & 54.69 \\
\hline 1953 & 224.0 & 191.5 & 32.5 & 57.21 \\
\hline 1954 & 262.6 & 230.0 & 32.8 & 76.98 \\
\hline 1955 & 267.3 & 228.9 & 38.5 & 58.80 \\
\hline 1956 & 281.8 & 218.4 & 63.4 & 66.38 \\
\hline
\end{tabular}

Fuente: Banco interamericano de reconstrucción y Fomento (BIRF) 1958. Situación Actual y Perspectivas de la Economla de El Salvador. Publicación Ministerio de Economia. Precios: Tomados de Revista Banco Central de Reserva de El Salvador. 
Los favorables precios del café en el mercado internacional habian posibilitado altos ingresos al sector exportador, el momento era propicio para reorientar parte del capital obtenido a nuevas actividades económicas, pero el carácter tradicional de este grupo no era sensible a cambios en sus puntos de inversión económica y siguió inicialmente orientando el excedente logrado a "mejorar los cafetales que habían sido descuidados durante el periodo recesivo, a la ampliación del cultivo, a compra de activos fijos (terrenos, casa, etc.), a reforzar la actividad financiera comercial y adquirir bienes suntuarios; el resto se depositó en el exterior; en 1945-1950 se exportó la suma de 61 millones de colones, es decir, el $11.2 \%$ del valor total de las exportaciones de café durante ese período". 6

\section{Cuadro No. 2 \\ Ingresos reales del sector exportador \\ Millones de colones}

\begin{tabular}{|c|c|}
\hline Afio & Ingreso real del sector exportador \\
\hline 1945 & 66.2 \\
1946 & 78.2 \\
1947 & 112.0 \\
1948 & 122.2 \\
1949 & 145.4 \\
1950 & 171.0 \\
1951 & 183.9 \\
1952 & 191.0 \\
\hline
\end{tabular}

Fuente: Naciones Unidas, Análisis y Proyecciones del Desarrollo Económico: VIII El desarrollo económico de El Salvador. México, 1959. Tomado de Dada, Héctor. La Economía de El Salvador y la Integración Centroamericana 1945-60, UCA Editores, Pág. 40.

Otro de los factores que estimuló la inversión en la actividad industrial fué la expansión del cultivo del algodón asi como el crecimiento de las exportaciones de este producto.

La superficie cultivada del algodón había crecido más de 3 veces de 1945 a 1960, los rendimientos y los precios se habian más que duplicado durante el periodo; esta actividad se vio estimulada por las condiciones favorables que presentaba el mercado externo en cuanto a la demanda y sus precios. Las exportaciones de algodón habían crecido más de 6 veces entre 1950 y 1956.

La situación bonanciable de la actividad algodonera se convertiría en 
un elemento mediador hacia las actividades industriales ya que ésta presenta un carácter de "industria agricola moderna que usa las técnicas más avanzadas, un relativamente poco uso de obreros agrícolas, y un relativamente intensivo uso de capital y además, con una posibilidad de rápida rotación del capital". 7

\section{Cuadro No. 3}

Algodón: Superflcie cultivada, rendimientos y precios 1945-60

\begin{tabular}{|l|c|c|c|c|c|c|}
\hline & 1945 & 1948 & 1951 & 1954 & 1957 & 1960 \\
\hline $\begin{array}{l}\text { Superficie } \\
\text { Miles de ha }\end{array}$ & 12.9 & 15.6 & 29.9 & 21.1 & 39.7 & 43.0 \\
Rendimiento & & & & & & \\
QQ/ha & 6.0 & 6.5 & 7.0 & 13.3 & 17.7 & 15.7 \\
Precio $₫ /$ Kgs. & 0.77 & 1.37 & 2.51 & 1.20 & 1.46 & 1.30 \\
\hline
\end{tabular}

Fuente: Dada, Héctor. La Economía de El Salvador y la Integración Centroamericana 1945-60. Pág. 32.

La producción de algodón representaria a su vez un crecimiento de la fuerza de trabajo asalariada y un aumento del grado de monetarización de la economia.

"Las vias de comunicación construidas o mejoradas para facilitar la expansión agrícola no sólo habilitan nuevas tierras para los cultivos de exportación y los de consumo interno: ellos crean una infraestructura que expande el transporte, disminuyendo costos a la exportación, a la vez unifican el mercado nacional favoreciendo la universalización de la monetarización de la economía". ${ }^{8}$

En general la expansión de la producción algodonera y sus efectos asociados (mecanización, monetarización, infraestructura, etc.) se convertiran en la mediación para volver atractiva la inversión de la industria para el grupo agro-exportador.

En el contexto internacional se presentarian (como lo mencionamos anteriormente) factores también estimuladores para el crecimiento industrial, el proceso de internacionalización de la producción y del capital requeria en la post-guerra de una dinámica de industrialización en los paises periféricos, dado el desarrollo de la producción industrial de bienes de capital e intermedios en los paises centrales hace necesario una redefinición de la actividad económica en los paises periféricos, acordes a una nueva división internacional del trabajo: la industrialización. 


\subsection{Factores desfavorables al proceso de Industriallzación}

En este ámbito habría que ubicar esencialmente dos factores negativos que podrían frenar las posibilidades de la industrialización en El Salvador: uno se refiere al carácter tradicional o conservador del grupo agroexportador en cuanto a nuevas inversiones fuera de la agricultura y especialmente fuera de la producción cafetalera; y el segundo se refiere a la estrechez del mercado interno.

Con respecto al primero se puede sef̂alar que el grupo agro-exportador presentaba las siguientes características: ${ }^{9}$

a) Estaba acostumbrado a mantener en forma líquida, grandes cantidades de dinero, lo cual significaba el poco interés por inversión real o movilización de sus capitales.

b) Su inversión estaba orientada fundamentalmente a tierras, industrias que producian artículos de exportación, en el comercio, en valores extranjeros y depósitos en el exterior.

c) No miraban la necesidad de un mercado de capitales y miraban con descontianza el comercio de valores.

d) Estaban acostumbrados a créditos a corto y mediano plazo y buscanban la rápida liquidación de activos mantenidos en valores.

e) Atribuian grandes riesgos a las inversiones en la industria, sobre todo a las nuevas industrias, no consideraban la necesidad de ampliar el mercado interno, estaban acostumbrados a altas tasas de ganancia y a corto plazo (aspectos que la agricultura de exportación le garantizaba).

Las características atribuidas al grupo exportador muestran las dificultades que podria presentarse para la industrialización, ya que a pesar de los altos ingresos que obtuvo este sector durante los afios ' 40 y principios de los ' 50 estos debieron verse estimulados por otros factores a fin de decidirse a nuevas alternativas productivas.

El segundo factor limitante del proceso industrial es el reducido mercado interno, el cual esta asociado a la concentración del ingreso. Este problema significa en el marco de la industrialización la incapacidad de un gran contingente de la población con bajos salarios e ingresos que no podrian consumir o demandar, una producción de las dimensiones que el proceso industrial requeria.

Al respecto se sefiala en base al cuadro №.4 que "el $8 \%$ de la población concentraba el $52 \%$ del ingreso bruto en 1950 , teniendo un ingreso percápita medio más de 20 veces superior al de la categoría $C$, que compuesto por el $61 \%$ de la población, recibe solamente el $19.5 \%$ del ingreso total". 10 
La estructura de distribución del ingreso en 1950 muestra evidencias sobre un problema que ha sido y es tradicional en El Salvador; una gran cantidad de población y familias con poco o ningún acceso al consumo de bienes durables, un grupo de familias reducido, con un alto nivel de ingreso y con potenciales de consumo muy grandes de bienes durables.

El estrato medio de ingresos que para el año 1950 estaba constituido por el $31 \%$ de la población también tiene ingresos promedio bajos, 167 dólares por persona, los cuales no garantizan "un mercado de las dimensiones necesarias para la producción de bienes duraderos, sector que pódía darle cierta dinámica al proceso de industrialización". ${ }^{11}$

Ciertamente, el problema de las limitaciones que tiene el mercado interno esta relacionado con el carácter concentrado de la propiedad de la tierra, que propicia una alta concentración del ingreso; por esta razón se considera que la actividad agro-exportadora genera al mismo tiempo factores favorables y desfavorables al proceso de industrialización.

Cuadro No. 4

Distribución del ingreso en El Salvador (1950)

\begin{tabular}{|c|c|c|c|c|}
\hline Categoria & $\begin{array}{c}\text { Población } \\
\%\end{array}$ & $\begin{array}{c}\text { ngreso bruto } \\
\%\end{array}$ & $\begin{array}{c}\text { Ingreso bruto } \\
\text { por persona us }\end{array}$ & $\begin{array}{c}\text { Indice de ingreso } \\
(100=\mathrm{Y} \text { medio) }\end{array}$ \\
\hline & & & & \\
A & 8 & 52 & 1.183 & 650 \\
B & 31 & 28.5 & 167 & 92 \\
C & 61 & 19.5 & 58 & 32 \\
Total & 100 & 100 & 182 & 100 \\
\hline
\end{tabular}

Fuente: Elaborado a base de datos de la Misión de Asistencia Técnica de las Naciones Unidas, "Medidas propuestas para fomentar el desarrollo económico en El Salvador," citadas en Naciones Unidas, "La Política Tributaria y el Desarrollo de Centroamerica". Los datos fueron obtenidos en base a muestreo. Tomada de Dada, Héctor. La Economía de El Salvador y la Integración Centroamericana 1945-1960. Pág. 44.

En conclusión podriamos señalar que existen factores que potencian el proceso de industrialización en EI Salvador a fines de la década de los ' 40 pero existen también limitantes. En este ámbito de contradicción, es que cobra importancia el papel Estado el que articulará un proyecto político-económico determinado, y a su vez establecerá los mecanismos estimuladores al logro de su proyecto y objetivos especificos.

\section{El proyecto politico-económico del Estado}


El golpe de Estado del '48 encontraba su base de sustentación en la proclama de principios y objetivos del Gobierno Revolucionario que en su conjunto "reflejaba a un nivel político, las aspiraciones que en el plano económico motivaron el hecho social". 12

Es decir, la proclama plantea tanto la necesidad del cambio politico, que a su vez era importante para posibilitar el desarrollo del proceso de acumulación a través de la industrialización. La declaración de "Construir una Patria pujante" y adherirse a la " gran corriente de la cultura occidental" nos señala el interés del Estado de impulsar acciones en torno al proceso de modernización de las estructuras de la sociedad salvadoreña.

La proclama considera además el establecimiento de un "nuevo orden jurídico plasmado en una Constitución Política" que permitiría adaptar los principios a la realidad salvadoreña, es decir, una legislación que propicie el adaptarse a los nuevos cambios que se operan en la sociedad moderna.

Existía además toda una concepción en busca del concenso social cuando se dice que se buscará elevar el "nivel de los salvadoreños sobre bases que garanticen el auge de la producción, al amparo del desarrollo técnico se estimule las empresas privadas y la justicia social". Este aspecto supondria la adhesión de los distintos grupos económicos y sociales con el nuevo rol del Estado.

El llamado a la "unidad de los salvadorefios en la reconstrucción y progreso de la patria " es otro punto importante de la proclama; y la vinculación de la sociedad civil y el ejército como necesidad para el desarrollo del proyecto político-económico, se convierten en puntos necesarios para lograr el objetivo general de "construir" la nueva economia.

Por último el carácter centroamericanista y el respeto a los Tratados, Convenios y Compromisos Intemacionales adquiridos anteriormente son el resultado de la necesidad de mantener un ámbito de relaciones externas provechosas para avanzar en el desarrollo económico del país.

En general, la Proclama no sólo es un enunciado de buenas intenciones del Gobierno que surge en el golpe de Estado, sino que existe todo un proyecto político donde las fuerzas económicas proclives a la modernización de la economía estás dispuestas a generar y crear mecanismos para el desarrollo del proceso de industrialización. Además si bien los sectores tradicionales agro-exportadores pudieron ver con recelo esta acción del Estado, parecían más bien dispuestos a ver el desarrollo de políticas que en nada perjudicarian sus mecanismos de acumulación, en tanto que no afectarían su actividad económica, esencial y más bien potenciaría su acumulación de capital.

El Estado del '48 plasma así un proyecto político y económico que se 
sustenta en la promoción de la industrialización en lo económico y en su carácter benefactor en lo social.

El otro aspecto que nos permite comprender la existencia de un proyecto político-económico definido por Estado es la Constitución Política de 1950. Esta constitución define una función más activa del Estado en la economia, dejando de alguna manera su rol tradicional de la administración pública.

El artículo No. 2 de la Constitución establece que: "Es obligación del Estado asegurar a los habitantes de la República el goce de la libertad, la salud, la cultura, el bienestar económico y la justicia social". Ciertamente, esto le define la necesidad al Estado de asumir un papel más importante en la "creación de riqueza del país y en la busqueda de rutas para el desarrollo de la sociedad". 13

La Constitución Política del '50 en sus componentes económicos determina a su vez el carácter más intervencionista que debe asumir el Estado, sefialemos algunos:

a) El Art. 135 (Título IX) del régimen económico determina que este "debe responder esencialmente a los principios de justicia social que tiendan a asegurar a todos los habitantes del pais una existencia digna de ser humano".

b) En otro artículo se reconoce la garantia de la "propiedad privada en función social". (Art. 137).

c) En el Art. 138 se establece "la expropiación siempre y cuando ésta obedeciera a causas de utilidad pública o interés social legalmente establecido y previa a una justa indemnización".

d) Art. 143 inciso 2do. El Estado como "orientador de la politica monetaria a fin de promover y mantener las condiciones más favorables para el desarrollo ordenado de la economía nacional".

e) Existen otros articulos que posibilitan al Estado el derecho de intervenir las empresas que prestan servicios esenciales a la comunidad y la intervención del Estado en los problemas de agro salvadorefio.

Esta nueva Constitución marcará desde el punto de vista juridico la posibilidad real del Estado de actuar más decididamente en la vida económica de la Nación.

A decir de algunos autores, "con la promulgación de la Constitución de 1950 el Estado surge como un personaje decisivo en la planificación de la vida económica del pais, impulsando una nueva programática que debe incentivar un desarrollo económico capitalista en el cual la iniciativa privada y la estatal deben converger y delimitar su zona de influencia, relegando la inversión pública a aquellos renglones en que la iniciativa pri- 
vada no quiere o no puede abordar en nuestro pais". 14

La misma Constitución Política establecía también un conjunto de artículos que posibilitaban la acción social del Estado, regulaciones en materia de familia, trabajo, salud, seguridad social, cultura, asistencia social, etc. planteaban así el carácter benefactor del Estado.

La Constitución se convertirá asi en un componente más, que define el proyecto político-económico del Estado del '48; la acción reguladora y acumuladora del Estado proclive a la industrialización y modernización de la sociedad salvadoreña está planteada en los elementos que propician la intervención del Estado en la economia; y por otro lado su acción social, que busca el concenso y legitimidad de su actuación está también presente en esta nueva Constitución Política.

\section{Los mecanismos propiciadores de la industrialización: El Estado promotor}

La presencia de factores favorables al proceso de industrialización tanto en el ámbito interno, como internacional, no eran suficientes para incentivar y desarrollar una inversión en gran escala en la industria; era necesario por lo tanto crear nuevos mecanismos que propiciaran la reorientación del capital agro-exportador hacia esta actividad.

En este sentido el Estado jugará un papel importante en el impulso y desarrollo industrial. El Gobieno surgido del Golpe de Estado de 1948 y los sucesivos Gobiernos de Osorio (1950) y de Lemus (1956) establecieron toda una base jurídica y una acción acumuladora en orden a fomentar la actividad industrial.

Tal como hemos señalado anteriormente la acción reguladora y acumuladora del Estado en este período (1948-60), se sustenta en la "Proclama de Principios y Objetivos del Gobierno Revolucionario del '48" y en la Constitución Política de 1950. Ambos documentos esbozan el nuevo rol del Estado en la "construcción de una Patria pujante" y el papel más activo del Estado en la creación de la riqueza nacional y el desarrollo de la sociedad.

Presentaremos ahora con relativo detenimiento, las medidas y mecanismos creados por el Estado para estimular la industrialización.

A partir de 1948, el Estado comienza a establecer una nueva legislación a fin de estimular "la organización o instalación de empresas industriales y se convierte deliberadamente en el guía y director de las inversiones privadas y del desarrolio nacional".

El ambiente proclive a la industrialización que se había ido gestanto a través de los años, con la presencia de grupos industrializantes (con cierto poder económico y político), asi como por la presencia del capital 
extranjero y por factores favorables a la industrialización hacian posible una acción más decidida del Estado en este campo.

Las medidas que el Estado, impulsa durante este periodo son:

a) En julio de 1949 se promulga la Ley de "Disposiciones sobre la Fabricación de Cemento" bajo el Decreto No. 188 del Gobierno Revolucionario.

El 17 Octubre de 1949 se fundó la primera Compafía elaboradora de Cemento Portland: Cemento de El Salvador, Sociedad Anónima," cuya planta se localiza en Acajutla.

"Desde 1925 se venian haciendo estudios para conocer la factibilidad de fabricar Cemento en el país, pero los promotores de esta actividad no lograron nunca el capital necesario por la falta de confianza de aquellas personas con capacidad de hacer inversiones en la producción industrial.

El capital inicial de esta empresa fué de 500,000 colones, dividido en acciones de diez colones cada una, para 1953 el capital social pagado asciende a cinco millones de colones". ${ }^{15}$

b) El Decreto No. 188 más allá de favorecer el establecimiento de fábricas de Cemento, se constituye en una Ley que proporciona concesiones a favor de las Companías que se organicen en forma de Sociedad Anónima.

Dicha Ley plantea los siguientes considerandos: 16

l) Que es función y deber fundamental del Estado estimular la actividad industrial del pais, con el fin de aprovechar los recursos naturales y humanos, elevar el nivel de vida de la población y fortalecer su independencia económica.

II) Que es necesario y ugente dictar todas las disposiciones apropiadas que vengan a estimular las inversiones de capital nacional y extranjero en el campo industrial.

Las concesiones que se establecen en esta Ley son:

1) "Franquicia de derechos consulares y de importación sobre maquinaria y materiales de construcción requeridas para el montaje de las fábricas de que se trate, implementos, combustibles y materias primas necesarias para la producción, siempre que no puedan producirse en el pais y aunque fueran producidas no puedan adquirirse;

2) El Estado no gravará con impuesto de exportación al cemento elaborado;

3) El Estado no concederá prerrogativas especiales a nuevas empre- 
sas productoras de cemento, ni las colocará en condiciones de superioridad sobre las existentes.

El Estado a su vez establecía que las fábricas de cemento deberian dar prioridad al Estado en sus ventas hasta el $50 \%$. Aspecto que garantizaba el mercado para estas empresas". ${ }^{17}$

c) Las Leyes de impuestos sobre la renta y de vialidad, 1951, 1953. El objetivo de la Ley de Impuesto a la Renta era estimular la formación de empresas en Sociedades, es decir al Estado le interesaba propiciar la asociación de capitales en las inversiones privadas. Al respecto se señala que "el Estado trataba de romper con esto, las formas tradicionales de inversión que por la renuencia a formar compañias colectivas por acciones orientaban sus fondos (de inversión) hacia el comercio y hacia bienes rurales y urbanos". 18

"La Ley de Impuesto a la Renta diferenciaba la carga tributaria a las personas naturales que podia llegar hasta $44 \%$ sobre la renta imponible y en cambio hasta un $5 \%$ en la renta imponible de las Sociedades Anónimas. A su vez podían presentarse excensiones de impuestos de ventas de sociedades cuyo origen proviene de otras sociedades; podian además deducir de la renta neta legal, las utilidades que se destinaron a la ampliación de las plantas o creación de nuevas industrias; podian deducir también el monto de intereses que percibian las instituciones de crédito por préstamos concedidos a empresas industriales". 19

En general esta Ley pretendía estimular la formación de sociedades anónimas y la reinversión en la actividad industrial. Es también importante considerar que la reforma a la Ley de Impuestos a la Renta permitía captar mayores ingresos para el desarrollo de las acciones del Estado, para el caso los ingresos tributarios por impuesto a la renta aumentaron de 2.66 millones de colones en 1946 a 10.63 millones de colones en 1954, un incremento de casi 4 veces en estos ingresos del Estado.

La Ley de Vialidad tenia como objetivo ser un impuesto sobre el capital, más que destinado a incrementar los ingresos del Estado. "Esta Ley dejaba exento de impuestos a los depósitos bancarios en el país. Con esto se pretendia estimular el ahorro que luego podría ser canalizado a actividades de inversión privada". 20

d) Ley de Fomento de Industria de Transformación. Se establece el 22 de Marzo de 1952 con el objeto de "promover el Desarrollo Industrial el cual podría elevar el nivel de empleo, de bienestar de la población y dar una base más sólida y estable a la economía nacional".

Esta Ley "crea cuatro tipos de empresas a ser favorecidas (iniciación 
necesaria, iniciación conveniente, incremento necesario e incremento conveniente), las cuales recibirán el derecho de dispensa de impuestos diversos (impuestos de importación de insumos, de bienes de capital y de materiales de construcción necesarios para realizar el incremento del capital y el funcionamiento de la producción, en casi todos los casos, pudiendo llegarse hasta la dispensa del impuesto al capital, el de la renta y beneficios y los de producción); los periodos de gracia van de 5 a 10 afios". 21

Entre 1953 y 1962 el total de tranquicias y beneficios otorgados por esta ley a las distintas Empresas fué de más de 14 millones de colones, llegando a constituir en el periodo un promedio de $1.0 \%$ de los ingresos tributarios del Gobierno y más del $2 \%$ de los derechos de importación.

\section{Cuadro No. 5}

Franquiclas dispensadas a las empresas acogidas a las leyes de fomento industrial

(Miles de colones)

\begin{tabular}{|c|c|c|c|c|c|c|c|c|c|c|c|c|}
\hline & & 1953 & 1054 & 1855 & 1956 & 1957 & 1058 & 1850 & 1860 & 1961 & 1862 & Tolw \\
\hline 1) & $\begin{array}{l}\text { Franquicias Oor- } \\
\text { gadas }\end{array}$ & 165.6 & 156.3 & 497.6 & 596.9 & 1041.3 & 730.9 & 1699.4 & 19124 & 24128 & 3814.4 & 13030.6 \\
\hline 2) & $\begin{array}{l}\text { Otros } \\
\text { Impuestos } \\
\text { Directos-e } \\
\text { Indirectos } \\
\text { Concedidos }\end{array}$ & - & - & 49.8 & 59.7 & 104.1 & 73.4 & 170.8 & \begin{tabular}{|l|}
191.2 \\
\end{tabular} & 241.3 & 381.4 & 1271.8 \\
\hline & $\begin{array}{l}1+2+\text { Ingreso } \\
\text { o Tributarios }\end{array}$ & 0.13 & 0.10 & 0.35 & 0.37 & 0.65 & 0.52 & 1.32 & 1.35 & 1.87 & 2.75 & Promodio \\
\hline & 1+ Derechos de & & 0.28 & 0.90 & 1.01 & 1.65 & 124 & 1.91 & 274 & 4.17 & 6.36 & $2 \%$ \\
\hline
\end{tabular}

Fuente: Conaplan. Consejo Nacional de Planificación: Documentos sobre la Industrialización en El Salvador. Diagnóstico del Sector Industrial, 19501962, El Salvador.

(1) Estimado en un 10\% de las franquicias concedidas.

En el mismo periodo según datos de CONAPLAN 335 empresas fueron amparadas por los "beneficios fiscales, los cuales representan el $13.3 \%$ de las 2,517 empresas industriales consideradas como manufactureras por el censo de 1961". 22 Del total de empresas acogidas a esta Ley, el $74 \%$ lo constituyen empresas calificadas como de iniciación necesaria y de incremento necesario, lo cual define la prioridad del Estado por favorecer a aquellas que se dedican a la producción de alimentos, textiles, vestuario, medicinas, etc. El capital declarado por 
estas 250 empresas es superior a los 238.7 millones de colones, es decir el $88 \%$ del capital declarado por todas las Empresas amparadas a la Ley.

La Ley de fomento de industrias de Transformación se constituye así en un mecanismo altamente favorable a la inversión industrial, la cual no discrimina a la inversión extranjera que también se acoge a los beneficios de esta Ley, al respecto se sefalaba que "la introducción de nuevas técnica y la experiencia de los capitales extranjeros en el desarrollo industrial, hacen en extremo necesario la participación de éste, pues no vale tener recursos, si se carece de ideas o empresarios capaces de desarrollar nuevos proyectos". ${ }^{23}$ La importancia que le da el Estado a la inversión extranjera, se manifestará en el crecimiento de este capital (especialmente durante la década de los '60) en la industria manufacturera. El capital extranjero en las Sociedades Anóminas manufactureras pasa de 3.2 millones de colones en 1950 a 31.1 millones de colones en 1963.

\section{Cuadro No. 6 \\ Beneficios concedidos por la Ley de Fomento de Industrias de Transformación según actividad y número de empresas (1953-1962)}

\begin{tabular}{|l|c|r|}
\hline \multicolumn{1}{|c|}{ Actividad } & Número de empresas & $\%$ \\
\hline & & \\
Productos Alimenticios & 102 & 30.4 \\
Textiles & 30 & 8.9 \\
Productos Quimicos & 50 & 14.9 \\
Productos Minerales & & \\
no Metálicos & 23 & 6.8 \\
Productos Metálicos & 35 & 10.4 \\
Otros & 95 & 28.3 \\
Total & 335 & 100.0 \\
\hline
\end{tabular}

Fuente: En base a datos de CONAPLAN. Diagnóstico del sector industrial 195062 El Salvador.

Tal como sefialabamos anteriormente los beneficios concedidos por la Ley de Fomento de Industrias de Transformación se orientan a la producción de alimentos, textiles y productos químicos, siendo aprovechadas por 182 empresas las cuales constituyen más del $50 \%$ del total de empresas beneficiadas. 
En general podemos considerar que la Ley de Fomento de Industrias de Transformación fué un mecanisno importante para dinamizar la actividad industrial en El Salvador y propiciar a su vez la inversión del capital extranjero en esta actividad.

e) Creación del Instituto Salvadoreño de Fomento de la Producción (INSAFOP). Creado en Septiembre de 1955, y comenzó a funcionar el 7 de Junio de 1956.

Su objetivo fundamental era satisfacer las necesidades de crédito a largo plazo no cubierto por empresas privadas, a tasas de interés menores que las comerciales.

Esta institución se convertiria en un mecanismo de financiamiento a mediano y largo plazo favorable a la inversión del capital privado, especialmente en la actividad industrial, complementando asi la politica de incentivos fiscales que se desarrolla mediante la Ley de Fomento de Industrias de Transformación.

INSAFOP "Proporcionará facilidades de crédito a la iniciativa privada para la realización de proyectos que arrojen un margen favorable de probabilidades de éxito, tanto en lo que se refiere a su vez costeabilidad desde el ángulo del inversionista, como el relativo al interés de la generalidad, y siempre que tales proyectos no sean atendidos satisfactoriamente por otras entidades públicas o privadas". ${ }^{24}$

También considera entre sus objetivos que el Instituto realizará investigaciones de carácter técnico, comercial y financiero para orientar las "actividades privadas a nuevas formas de producción agricola e industrial, que urge desarrollar en el país para satisfacer las necesidades de consumo interno y para crear fuentes de trabajo remunerado para la población". ${ }^{25}$

La importancia que asume esta institución está en el fomento directo $e$ indirecto a la actividad industrial, dado que se incentivaria la producción, conservación y distribución de alimentos básicos para el consumo nacional; se fomentará la producción agrícola y ganadera, especialmente cuando se trate de materias primas para el desarrollo industrial, se beneficiará la producción textil y de vestuario, así como de materiales de construcción de viviendas y se rehabilitará la producción minera.

También se considera que el Instituto procurará el establecimiento de refinerias y talleres industriales o de tipo artesanal que utilicen materias primas producidas en las minas del pais; fomentará la producción de fertilizantes, insecticidas, fungicidas y otros productos; a su vez dará facilidades para la adquisición de equipo,materias primas o productos semi-elaborados de origen extranjero para la agricultura e 
industria y colaborará con la Comisión Hidroeléctrica del Río Lempa en el desarrollo y aprovechamiento de los recursos eléctricos del pais.

En general se trata de una política de financiamiento favorable a la inversión privada, especialmente en la actividad industrial, ya sea bajo

\section{Cuadro No. 7 \\ INSAFOP: Número y montos de los créditos concedidos} (Miles de colones)

\begin{tabular}{|c|c|c|}
\hline Años & Número de créditos & Monto de créditos \\
\hline & & \\
1957 & 11 & $2,031.0$ \\
1958 & 22 & $2,375.7$ \\
1959 & 28 & $2,317.9$ \\
1960 & 66 & $1,174.7$ \\
1961 & 100 & $2,173.7(1)$ \\
\hline
\end{tabular}

Fuente: CONAPLAN. Diagnóstico del Sector Industrial 1950-62, EI Salvador.

(1) No se incluye el crédito de 5 millones concedidos a COPAL.

el fomento directo a esta actividad o a través del financiamiento de actividades agricolas generadoras de materias primas para la industria.

Entre 1957 a 1961 el número de créditos proporcionados por INSAFOP se multiplicó casi por 10 , mientras que el monto promedio anual de los créditos se situaba en 2 millones de colones. Esto posibilitó también la expansión de la actividad industrial dado las caracteristicas y prioridad de objetivos de la institución.

Durante el período considerado (1956-61) INSAFOP, proporcionó una parte importante de crédito a inversión en la agricultura y la ganadería y su industrialización; la industrial textil de vestuario; a la industria de alimentos y a la industria de productos quimicos y farmaceuticos. De un total de 15.4 millones de colones de créditos concedidos, las actividades agrícolas e industriales anteriormente citadas habian absorbido más del $55 \%$ de dichos créditos.

Otras actividades también financiadas aunque en menor proporción fueron: un proyecto de electricidad (aspectos necesarios al proceso de industrialización), la industria peletera, indusfrias del cartón y artes gráficas, industrias de materiales para la construcción de viviendas y productos de madera, etc.

El financionamiento público orientado a través de INSAFOP fué tam- 
bién un mecanismo que proporciona ventajas a la inversión en la industria, asi el Estado sigue fortaleciendo y promoviendo el proceso de industrialización a través de recursos financieros de adecuado acceso y alta rentabilidad para los empresarios.

f) Construcción de carreteras y una presa hidroeléctrica. Completando la acción reguladora del Estado, este asume en el periodo un gasto público importante en obras de infraestructura que beneficiaran la inversión de capital privado. Se mejora en este periodo la red de carreteras, especialmente se construyó la carretera litoral; el objetivo de esta acción acumuladora era la unificación de los centros de producción con los mercados potenciales, eliminar las díficultades de transporte y comunicaciones entre las distintas regiones del pais, asi como favorecer el comercio con otros paises.

La construcción de la carretera litoral posibilitaria a su vez la incorporación de nuevas tierras al cultivo del algodón, actividad que se presentaba en rápido crecimiento. Esta carretera se financió a través de préstamos externos.

La construcción de la presa hidroeléctrica sobre el Rio Lempa, que también fué financiada por préstamos externos del BIRF, "proporcionaria energia suficiente para garantizar el suministro en forma regular y disminuiria su precio en un $25 \% "$. ${ }^{26}$ Esta inversión pública significó para el proceso de industrialización, la posibilidad de contar con un insumo importante y a bajo costo que estimularía así la inversión privada.

g) Liquidación de toda forma de cancelación de salarios en especies, lo cual permitió completar la monetarización de la economia, que se venía dando a través de la integración de los distintos mercados nacionales mediante la creación de infraestructura y la expansión del cultivo del algodón que introduce relaciones salariales en zonas donde antes dominaba el latifundio.

h) La derogación de las Leyes que restringian el proceso de acumulación de capital en todo un conjunto de actividades.

Durante los af́os '30 se habia creado una serie de Leyes que pretendian proteger a la pequeña industria y comercio salvadorefio. Un ejemplo al respecto se encuentra en el Art. 1 de la "Ley de Medidas de Protección al pequefío Comercio e Industria Nacional" que sefialaba que "toda persona natural o jurídica que negocie o comercie con un capital de veinte mil colones, si fuere salvadoreño o con cualquier capital si fuere extranjero, no podria dedicarse a ninguna actividad industrial 0 comercial de las que han sido o son el patrimonio del pequeno industrial o comerciante salvadoreno". 27 
En general, si bien estas Leyes pretendian proteger o evitar la destrucción de la producción artesanal, estas a su vez se convertian en un freno a la inversión en mayor escala en actividades fuera de la agricultura. Era por tanto necesario eliminar los mecanismos que restringen el proceso de acumulación en la industria y crear otros que la estimulen.

i) "Aumento de los impuestos a la exportación de café que permitiría un proceso de traslación del excedente del sector agro-exportador a otros sectores". 28

Las reformas que se establecieron al impuesto de exportación de café posibilitaron incrementar los ingresos tributarios del Estado por exportaciones de 8 millones de colones en 1948 a 43.5 millones de colones en 1956. Los impuestos de exportación pasaron así de constituir el $17.3 \%$ del total de ingresos tributarios en 1948, al $32.1 \%$ en 1956.

La relevancia que cobra el impuesto a la exportación entre los ingresos tributarios del Estado y especialmente el impuesto al café, permite al Estado obtener mayores recursos que podrán ser orientados a través de su política de gasto a obras públicas y fomento económico necesarios al proceso de industrialización.

j) El crecimiento del Gasto Público. Durante los anios '50 el gasto público del Estado se orientó en una proporción creciente al establecimiento de los medios necesarios a la expansión industrial y la diversificación productiva.

El gasto público de fomento casi se duplico entre 1950 y 1956 pasó de 42.2 millones de colones a 79 millones de colones entre los años considerados; el gasto en la administración general también se incremento como factor necesario a la implementación o regulación de las actividades necesarias al proceso que el Estado desarrollaba. Este gasto pasó de 34.1 millones de colones en 1950 a 55 millones de colones en 1956.

Específicamente el gasto en obras públicas y fomento económico aumentó en casi un 50\% entre 1950 y 1956 favoreciendo asi la política del Estado hacia la actividad industrial (ver cuadro No. 8) para 1950 el gasto en obras públicas era de 19.6 millones de colones, mientras que para 1957 este alcanzó a ser de 30.5 millones de colones.

k) Establecimiento de Convenios Comerciales. Los Convenios Comerciales se convirtieron en medidas orientadas a la necesidad de expandir el mercado de manufacturas que se iria desarrollando a través de la 
década de los '50, a su vez serviria para la obtención de materias

Cuadro No. 8

Gastos públicos por grupos de destino 1950-56

(Millones de colones)

\begin{tabular}{|c|c|c|c|r|c|c|c|c|c|c|}
\hline Año & $\begin{array}{c}\text { Admón. } \\
\text { general }\end{array}$ & $\%$ & Defensa & $\%$ & $\begin{array}{c}\text { Gastos } \\
\text { de } \\
\text { fomento }\end{array}$ & $\%$ & $\begin{array}{c}\text { Deuda } \\
\text { públlca }\end{array}$ & $\%$ & Tolal & $\%$ \\
\hline & & & & & & & & & & \\
1950 & 34.1 & 34.8 & 9.9 & 11.2 & 42.2 & 47.6 & 2.8 & 2.8 & 87.7 & 100.0 \\
1951 & 45.9 & 37.8 & 11.9 & 9.8 & 58.9 & 58.5 & 4.8 & 4.8 & 121.5 & 100.0 \\
1952 & 49.1 & 38.4 & 12.3 & 9.6 & 61.6 & 48.1 & 4.8 & 3.8 & 127.8 & 100.0 \\
1953 & 51.0 & 37.5 & 15.1 & 11.1 & 65.2 & 47.9 & 4.8 & 3.5 & 136.1 & 100.0 \\
1954 & 44.4 & 28.8 & 19.4 & 12.7 & 85.5 & 55.2 & 4.7 & 3.2 & 154.0 & 100.0 \\
1955 & 48.4 & 31.6 & 16.2 & 10.6 & 78.6 & $\mathbf{5 1 . 2}$ & 10.2 & 6.6 & 153.4 & 100.0 \\
1956 & 55.0 & 35.9 & 15.9 & 10.4 & 79.0 & 51.7 & 3.1 & 2.2 & 153.0 & 100.0 \\
\hline
\end{tabular}

Fuente: 1950-1956 Ministerio de Hacienda. Informe complementario Constitucional, Anuario Estadístico, 1954, Pág. 175.

1955-1956 Informe Financiero del año 1955. Tomado de Banco Interamericano de Reconstrucción y Fomento (BIRF). Situación Actual y Perspectivas de la Economía de El Salvador. Públicación Ministerio de Economla.

primas, equipo, maquinaria, etc. importantes para el crecimiento industrial.

Es importante señalar que el limitado mercado interno, que si bien el Estado trataba de expandir, se convertia en un freno al desarrollo industrial, este podría ampliarse fuera de las fronteras nacionales, por eso la importancia de los Convenios Comerciales suscritos durante el período.

Durante este período 1950-60 los Convenios Comerciales tirmados por El Salvador se caracterizan por ser bilaterales basados esencialmente en la concepción de las ventajas aduaneras y la creación del libre comercio entre los dos paises.

Entre los tratados bilaterales firmados tenemos:

- En Marzo de 1951 se firma el Tratado con Nicaragua;

- En Diciembre de 1951 se firma el Tratado con Guatemala;

- En octubre de 1953 con Costa Rica; y

- En Febrero de 1957 se firma un nuevo Tratado con Honduras. 
El balance de Comercio Exterior de El Salvador en el periodo de 19481960 muestra la incidencia que estos Convenios tuvieron en la expansión de las exportaciones a la región Centroamericana. El saldo comercial de El Salvador muestra una situación positiva desde 1948 a 1959 (ver cuadro $N^{9}$.9.) Las exportaciones crecieron más de 2.5 veces y las importaciones en 2.9 veces. El saldo positivo de la relación comercial con el exterior aumento de $\mathbf{1 0 . 2}$ millones de colones hasta 34.6 millones entre 1948 y 1959 respectivamente.

En general este mecanismo de convenios comerciales con el exterior fué un factor más que impulsó el desarrollo industrial.

El conjunto de medidas consideradas anteriormente, fueron ciertamente mecanismos importantes para el desarrollo de la actividad industrial,

Cuadro No. 9

Comercio exterior de El Salvador 1948-1960

(Millones de colones)

\begin{tabular}{|c|c|c|c|}
\hline Afio & Exportaciones & Importaciones & Saldo \\
\hline 1948 & 114.0 & 103.8 & 10.2 \\
1949 & 137.4 & 102.0 & 35.4 \\
1950 & 173.8 & 121.7 & 52.1 \\
1951 & 213.8 & 162.6 & 51.2 \\
1952 & 220.7 & 176.4 & 44.3 \\
1953 & 224.0 & 183.5 & 40.5 \\
1954 & 162.6 & 216.9 & 45.7 \\
1955 & 267.3 & 229.7 & 37.6 \\
1956 & 281.8 & 261.8 & 20.0 \\
1957 & 346.2 & 287.6 & 58.6 \\
1958 & 290.1 & 270.1 & 20.0 \\
1959 & 283.4 & 248.8 & 34.6 \\
1960 & 292.0 & 306.0 & -14.0 \\
\hline
\end{tabular}

Fuente: Boletín del Instituto Salvadoreño de Comercio Exterior.

asi la acción reguladora y acumuladora del Estado esta presente a través de este periodo, promoviendo el proyecto político-económico que el Gobierno del ' 48 habia estructurado desde su proclama de principios y objetivos.

Otro aspecto importante a considerar en el proceso de creación de medios y mecanismos para el desarrollo industrial, es ubicar el conjuto de 
instituciones y otras leyes que garantizaron el logro de los objetivos del proyecto. Entre estos podemos senalar:

a) Ley de Creación de la Dirección General de Comercio, Industria y Mineria en 1950.

b) Ley de la Industria Hotelera 1953

c) Ley de Fomento de Teatros y Cine 1954

d) Ley de Pesca y Carga Marítima 1955

e) Creación del ICAITI (Instituto Centroamericano de Investigación Tecnológica Industrial) 1956

f) Creación del Instituto Regulador de Abastecimientos (IRA) 1950

g) Creación de la Comisión Ejecutiva Portuaria Autónoma CEPA 1952

h) Creación del Instituto de Vivienda Umana IVU 1950

i) Creación del Instituto Salvadoreno del Seguro Social 1949

j) Creación de la Fábrica de Hilados y Tejidos de San Miguel 1949

k) Creación del Instituto de Colonización Rural 1950.

Las Instituciones creadas y las Leyes favorecian en una mayor proporción la modernización de la estructura productiva y la industrialización. El Estado a nivel de su estructura organizativa se va complejizando dadas las exigencias que el desarrollo económico requiere.

Es importante señalar que el Estado sigue también garantizando el desarrollo del sector agro-exportador, pero propicia a su vez la reorientación de los excedentes de esle sector hacia otras actividades económicas como la industria a fin de promover el crecimiento económico.

El Estado, asi promueve mediante su acción reguladora y acumuladora el proceso de crecimiento económico y el desarrollo de la actividad industrial.

\section{Proyecto polítlco-económico, concenso social y bienestar}

El Estado que surge del golpe del ' 48 había logrado delinear un proyecto político-económico que se orientaba a la reestructuración del aparato productivo sobre la base de la industrialización y diversificación económica. A su vez habia logrado crear los mecanismos económicos e institucionales necesarios al impulso y estímulo del nuevo proceso de acumulación.

Pero esta nueva lógica de crecimiento económico, requería también de un marco de estabilidad política y social que propiciaria las inversiones nacionales y extranjeras en mayor escala, eliminando asi los riesgos 
y la incertidumbre que los problemas sociales podrian crear a estas nuevas inversiones.

El Estado, buscará así el concenso social y generará los medios necesarios para el logro del "bienestar social" a fin de garantizar la estabilidad que el proceso requería.

\subsection{El concenso soclal y el blenestar}

Las contradicciones entre los grupos tradicionales agro-exportadores y el grupo pro-industrializante antes de 1948, habia llevado a la necesidad de alianzas entre los grupos más modernizantes de la clase dominante y otras fuerzas sociales, especialmente con los sectores medios urbanos, entre los cuales se pueden considerar: "el sector estudiantil, que prestó su capacidad agitadora al movimiento político de aquellos años (1944-1948); los sectores profesionales; los sectores militares, con los cuales se llegaria a formar la base estructural de la estabilidad política del período; la alta jerarquia eclesiástica; industriales, artesanos y obreros". 20

"Esta alianza hace posible luego de una tenaz huelga de brazos caidos en 1944, derrocar a Maximiliano Hernández Martinez que llevaba 13 años consecutivos en el poder político del país". 30 Los siguientes años seguirán siendo de inestabilidad política, golpes de Estado y mecanismos represivos a fin de frenar el desarrollo organizativo de los trabajadores. Será hasta 1948 cuando esta alianza posibilita la instauración de un nuevo Gobierno.

El movimiento sindical en 1948 luego del golpe de Estado "ofrece su apoyo condicional al Gobierno, presentando las siguientes demandas: libertad de organización sindical, legislación de trabajo, restablecimiento de libertades democráticas, regreso de los exiliados políticos y cese de las perscecusiones. Toda la lucha desemboca en la aprobación de una nueva Constitución Política en 1950 en la cual se establecen los Derechos Sociales de los trabajadores: a formar sindicatos, igualdad de salarios para igual trabajo, descanso remunerado, vacaciones anuales pagadas, consideraciones especiales a la mujer y menores de edad, indemnizaciones por despido injustificado, prestaciones a la mujer por maternidad, indemnización por accidentes de trabajo, seguro social, contrato de aprendizaje, protección del trabajador a domicilio, doméstico y agricola, contratos y convenciones colectivas de trabajo, derecho de huelga, jurisdicción especial del trabajo". ${ }^{31}$

El Estado reconstitutivo en 1948 contaba con márgenes temporales para la realización de su proyecto y para establecer los mecanismos que garanticen la "estabilidad politica " y el relativo bienestar de la población"

En este período el gobierno establece una legislación propicia a los 
sectores laborales, los cuales habian presionado durante muchos años por estar reinvindicaciones; entre estas podemos citar: ${ }^{32}$

a) Ley de Contratación Individual de Trabajo en Empresas y Establecimientos Comerciales e Industriales. 1949.

b) Ley de Seguro Social 1949 reformada en 1953

c) Ley de Procedimientos de Conflictos Individuales de Trabajo 1949

d) Ley de Sindicatos 1950 y 1951

e) Ley de Contratación Colectiva de Trabajo 1950 y 1952

f) Ley de Inspección de trabajo 1950

g) Ley de Procuración del Trabajo 1950

h) Ley Orgánica del Ministerio Público 1952

i) Lej de Jornadas de Trabajo y de Descanso Semanal 1952

j) Ley de Riesgos Profesionales 1956

k) Ley de Seguridad e Higiene en el trabajo 1956

l) Proyecto de Ley de Salario Minimo para Trabajadores del Campo 1960

Todas estas leyes trataban de "reglamentar, ordenar y legislar sobre casi todos los aspectos de trabajo industrial y comercial," pero no asi en el sector rural donde se prohibía la sindicalización campesina y donde el grupo agro-exportador había establecido los límites del Estado promotor.

En su conjunto estas leyes expresaban la necesidad de "una reorganización de la fuerza de trabajo" acorde a las necesidades de desarrollo industrial y de un marco de relaciones capitalistas. La estabilidad política podria también garantizarse a fin de incrementar las inversiones.

La búsqueda del concenso social por parte del Estado para la implementación de su proyecto, debia pasar a su vez por una serie de acciones que lograran crear las condiciones mínimas de bienestar económicosocial; en este campo el Estado crea instituciones y desarrolla una política de gasto social importante.

En 1950 se crea el Instituto Regular de Abastecimiento que permitiria controlar relativamente los precios de los productos de consumo básico para la población, pero al mismo tiempo serviría para mantener el costo de la mano de obra urbano en el margen adecuado a los requerimientos de las empresas industriales.

En este mismo año se creó el Instituto de Vivienda Urbano (IVU) que comenzó la construcción de viviendas con el objeto de generar empleo y "estabilizar la fuerza laboral en los centros urbanos más importantes". 33 
Uno de los objetivos del IVU era "fomentar la provisión de viviendas urbanas para familias de escasos y medianos recursos económicos". ${ }^{34} \mathrm{Si}$ bien se habia construido entre 1951 a 1960 más de 5,000 viviendas estas tenían un costo promedio en el periodo de 7,950 colones lo cual parece no ser favorable a una gran cantidad de población urbana de bajos ingresos y a una creciente población migrante y urbana. Ciertamente las políticas sociales del Estado tiene efectos en relación a sus objetivos generales de industrialización y crecimiento económico, más no es igual en términos de resolver los problemas de una gran mayoría de la población.

Otro de los mecanismos que utiliza el Estado, a fin de promover el bienestar social se puede ver a través del destino del gasto de fomento entre 1950 y 1956.

\section{Cuadro No. 10 \\ IVU: Número de viviendas y costo promedio en colones}

1951-1960

\begin{tabular}{|c|c|c|}
\hline Año & Número & Costo promedio \\
\hline 1951 & 992 & $6,030.96$ \\
1952 & 525 & $6,049.96$ \\
1953 & 921 & $10,956.46$ \\
1954 & 190 & $6,282.72$ \\
1955 & 143 & $5,790.5$ \\
1956 & 626 & $7,199.59$ \\
1957 & 478 & $7,235.75$ \\
1958 & 582 & $9,756.24$ \\
1959 & 337 & $10,350.19$ \\
1960 & 324 & $9,852.59$ \\
\hline
\end{tabular}

Fuente: Arrivillaga, Oscar. EI IVU ante el problema habitacional en EI Salvador. Tesis Arquitectura. Universidad de El Salvador. Tomado de Lungo, Mario. El Salvador, 1932-1978 La crisis del Estado y el papel de las políticas sociales. 1978 pág. 7.

Los gastos en Salud, Educación y Bienestar Social aumentaron en casi dos veces durante el periodo, llegando a constituirse en promedio en el $47.8 \%$ del gasto de fomento del gobierno. Agregando a estos, los gastos en Pensiones y Seguridad Social tambièn se incrementaron de $2.4 \mathrm{mi}-$ llones de colones en 1950 a 13.1 millones de colones en 1956, llegando a absorber en promedio alrededor del $12 \%$ del gasto de fomento.

Esta política de gasto en relación al bienestar social en general, significó la atención importante que el Estado presta al logro de la estabilidad política y la búsqueda del concenso social para garantizar el crecimiento 
Cuadro No. 11

Gastos de fomento por destino: 1950-1956

(Millones de colones)

\begin{tabular}{|c|c|c|c|c|c|c|c|}
\hline Año & $\begin{array}{c}\text { Obras } \\
\text { públlcas } \\
\text { fomento Econ. }\end{array}$ & $\%$ & $\begin{array}{c}\text { Salud, Educa- } \\
\text { clón y blenes- } \\
\text { tar social }\end{array}$ & $\%$ & $\begin{array}{c}\text { Penslón y } \\
\text { segurldad } \\
\text { Soc. }\end{array}$ & $\%$ & Total \\
\hline & 19.6 & 46.4 & 20.2 & 47.8 & 2.4 & 5.8 & 42.2 \\
1950 & 29.0 & 49.2 & 27.1 & 46.0 & 2.8 & 4.8 & 58.9 \\
1951 & 22.3 & 36.2 & 30.2 & 49.0 & 9.1 & 14.8 & 61.6 \\
1952 & 24.1 & 36.9 & 30.7 & 47.0 & 10.4 & 16.1 & 65.2 \\
1953 & 29.7 & 34.7 & 44.2 & 51.6 & 11.6 & 13.7 & 85.5 \\
1954 & 29.8 & 37.9 & 36.1 & 45.9 & 12.7 & 16.2 & 78.6 \\
1955 & 28.4 & 35.9 & 37.5 & 47.4 & 13.1 & 16.7 & 79.0 \\
1956 & & & & & & & \\
\hline
\end{tabular}

Fuente: Op. Cit. BIRF

- Porcentajes en relación al total del gasto de fomento por cada año.

industrial.

En general la acción estatal en la búsqueda del concenso social no solamente se estructuró sobre las bases de mecanismos de beneficio social, sino que también tuvo que recurrir a otros medios en la medida que el movimiento obrero presionará para "la constitución de Federaciones y Confederaciones, e incluso los sindicatos de industria". ${ }^{35}$

A partir de 1952, el gobierno "inicia una serie de maniobras no ya para romper el movimiento sindical urbano,..., sino pará coparlo en su dirección dominarlo orgánicamente e ideológicamente y aprovecharse del mismo para sus propios proyectos".

"El gobiemo habia preparado cuadros sindicales con la AFL-CIO con sede en Estados Unidos, la cual se había convertido en su asesora en aspectos laborales junto con la ORIT". 36

La represión también se habia presentado en 1951 y 1952, son exiliados varios dirigentes obreros, estudiantes y politicos, se ilegaliza la CROSS (Comité de Reorganización Obrero Sindical).

Para 1957 en el Primer Congreso Sindical Nacional el gobierno intenta la división del movimiento obrero, surgiendo como respuesta la Confederación General de Trabajadores de EI Salvador (CGTS), la cual aprueba una serie de reinvindicaciones como: obtener la aprobación de leyes laborales y reformas a las existentes, promulgación del Código de Trabajo, libre sindicalización urbano y rural, etc.

Este proceso de Movimiento Obrero Sindical obliga al gobierno y la 
ORIT a constituir en 1958 la Confederación General de Sindicatos de EI Salvador (CGSS). ${ }^{37}$

Es decir, el Estado establece a través del período nuevos mecanismos para coaptar el Movimiento Sindical y reorientarlo en la lógica del desarrollo de su proyecto, más los límites que presenta el modelo diversificador e industrializante a fines del periodo obligará al Estado a buscar nuevas formas de dinamizar el proyecto a través de la Integración Centroamericana y otros mecanismos políticos y sociales.

En general el Estado creó relativo concenso social y bienestar, a través de las leyes, el gasto público, mecanismos político-ideológicos y coercitivos que propiciaron el clima necesario al desarrollo del proyecto industrializante.

\section{Efectividad de la politica estatal}

Se trata de evaluar si la acción estatal tanto en el campo regulador como acumulador fué lo suficientemente eficaz y efectiva para el logro del proceso de modernización, industrialización y diversificación de la estructura económica.

También será necesario establecer si la creación de instituciones públicas, así como la participación del Estado en la economía promovieron con efectividad los ámbitos del crecimiento industrial y el logro de la estabilidad político social, necesarias al desarrollo adecuado del proyecto.

\subsection{El grado de industrialización}

El llamado "Estado promotor" de la industrialización, contribuyó a través del conjunto de políticas y medidas al logro de este objetivo. Entre 1950 y 1960 la producción industrial aumentó 1.6 veces, creciendo a una tasa promedio anual de $5.1 \%$ superior al crecimiento de $4.3 \%$ del producto territorial bruto en el mismo periodo.

La industria habia cobrado una gran importancia, su ritmo de crecimiento era superior a cualquiera de los otros sectores de la economia. El grado de industrialización que adquiere la economia salvadoreña es ascendente, de $13.5 \%$ que representaba la participación de la industria en la economía en 1950 pasa a $14.5 \%$ en 1960 .

Otro indicador de importancia para medir la dinámica del proceso de industrialización es el coeficiente de industrialización que para el periodo es de 1.18, el hecho que sea superior a la unidad demuestra que la industria se ha desarrollado más que la economía en su conjunto.

Ciertamente, el impulso y desarrollo industrial de la década del '50 fomentado deliberadamente por el Estado y bajo el interés de los grupos económicos que veian en esta actividad la posibilidad de diversificar sus 


\section{Cuadro No.12}

EI Salvador: Producto territorial bruto,producto manufacturero, grado de Industriallzaclón y coeficiente de industrialización 1950-1960 (En millones de colones)

\begin{tabular}{|c|c|c|c|c|c|c|}
\hline Año & $\begin{array}{c}\text { Producto } \\
\text { territorlal } \\
\text { bruto }\end{array}$ & \%РTB & $\begin{array}{c}\text { Producto } \\
\text { manufactura }\end{array}$ & \%P.M. & $\begin{array}{c}\text { Grados de* } \\
\text { Industrialización }\end{array}$ & $\begin{array}{c}\text { Coeficiente de } \\
\text { Industrial."* }\end{array}$ \\
\hline $\begin{array}{l}1950 \\
1951 \\
1952 \\
1953 \\
1954 \\
1955 \\
1956 \\
1957 \\
1958 \\
1959 \\
1960\end{array}$ & $\begin{array}{r}903.2 \\
956.8 \\
1,018.0 \\
1,044.8 \\
1,077.7 \\
1,124.1 \\
1,191.7 \\
1,258.8 \\
1,271.8 \\
1,328.9 \\
1,382.7\end{array}$ & $\begin{array}{l}5.9 \\
6.3 \\
2.6 \\
3.1 \\
4.3 \\
6.0 \\
5.6 \\
1.0 \\
4.4 \\
4.0\end{array}$ & $\begin{array}{l}122.4 \\
128.6 \\
140.9 \\
144.3 \\
151.7 \\
156.2 \\
157.3 \\
182.5 \\
180.9 \\
181.8 \\
200.5\end{array}$ & $\begin{array}{r}5.1 \\
9.6 \\
2.4 \\
5.1 \\
3.0 \\
7.1 \\
9.1 \\
-0.9 \\
0.5 \\
10.3\end{array}$ & $\begin{array}{l}13.5 \\
13.4 \\
13.8 \\
13.8 \\
14.1 \\
13.8 \\
13.1 \\
14.4 \\
14.2 \\
13.6 \\
14.5\end{array}$ & $\begin{array}{r}0.86 \\
1.52 \\
0.92 \\
1.64 \\
0.69 \\
1.18 \\
1.62 \\
-0.90 \\
0.11 \\
2.57\end{array}$ \\
\hline $\begin{array}{l}\text { omedio } \\
50-1960\end{array}$ & & 4.3 & & 5.1 & 14.0 & 1.18 \\
\hline
\end{tabular}

Fuente: Elaborado en base a datos del Banco Central de Reserva de El Salvador Conferencias Conmemorativas 50 Aniversario de Fundación Junio 1884.

- Grado de Industrialización: Producto Manufactura entre el producto territorial bruto.

* Coeficiente de Industrialización: Tasa de crecimiento industria entre tasa de crecimiento de la economía global. Si es mayor a la unidad la industria se desarrolló más que la economía nacional.

inversiones y obtener un alto grado de rentabilidad, se manifestaba también a través de otros indicadores.

El número de establecimiento en la industria manufacturera había aumentado de 8,242 en 1951 a 11,423 en 1956 y a 36.644 en 1961, un crecimiento de más de 4 veces entre 1951 y 1961. El personal ocupado había ido ascendiendo progresivamente en la medida que la industria crecía, multiplicandose por 2.1 la ocupación entre 1951 y 1961. En general las remuneraciones pagadas y el valor de las materias primas utilizadas en la industria se habian más que duplicado.

El acelerado ritmo de crecimiento de la industria durante este periodo (1948-1960) estaba enmarcado en el proyecto económico que sustentaba el gobierno, los mecanismos creados por el Estado garantizaron este auge industrial; ciertamente las condiciones internas, externas y la acción estatal propiciaron este desarrollo.

\subsection{Diversificación o sustitución de importaciones}


Cuadro No. 13

Industria manufacturera (1951-1961)

\begin{tabular}{|l|r|r|r|}
\hline \multicolumn{1}{|c|}{ Indicadores } & \multicolumn{1}{c|}{1951} & \multicolumn{1}{c|}{1956} & \multicolumn{1}{c|}{1961} \\
\hline 1. Número de Establecimientos & 8,242 & 11,423 & 36,644 \\
2. Personal Ocupado & 54,525 & 63,616 & 118,782 \\
3. Remuneraciones pagadas & 26,444 & 38,707 & 57,918 \\
4. Valor Materias Primas & 242,113 & 410,009 & 489,349 \\
5. Valor Agregado & 129,952 & 172,516 & 297,576 \\
\hline
\end{tabular}

Fuente: Ministerio de Economia, DIGESTYC. Primer Censo Industrial y Comercial (Vol. I); Segundo Censo Industrial y Comercial, 1956 (Vol. I); Tercer Censo Industrial y Comercial, 1961.

- Indicadores 3 a 5 miles de colones.

Mientras la industria crecia, esla iba asumiendo a su vez ciertas características propias del proceso de sustitución de importaciones y de la concentración económica de la estructura productiva en la cual se enmarcaba.

Es indudable que la industria cobra relevancia dentro de la participación de la producción total, pero no supera la importancia que sigue manteniendo la agricultura en el conjunto de la economia. Entre 1950 y 1960 la agricultura habia reducido su participación de $38.2 \%$ a $30.8 \%$ para los respectivos afios, mientras la industria pasaba de $13.5 \%$ a $14.5 \%$ en los últimos años. Otros sectores económicos se habian expandido como el cornercio, la construcción, el transporte, etc.; pero la economia en su conjunto seguia descansando en la actividad agrícola.

El relativo grado de diversificación de la economia, contrasta con el mayor nivel de diversificación que presenta la actividad industrial. En el cuadro №.14 se muestra la importancia que asumen algunas agrupaciones de las ramas industriales para el caso se señala que: la agrupación A (que incluye la industria de alimentos, bebidas, tabaco, textiles, calzado, vestuario, etc.) proporcionaba el $90.4 \%$ del valor agregado del sector en1950, este porcentaje va disminuyendo en la medida que el proceso de acumulación industrial avanza, hasta situarse en $82.7 \%$ en 1960.

La agnupación $B$ (incluye industrias de papel, caucho, minerales no metálicos y minerales metálicos) que presentaba el $2.5 \%$ en 1950 pasó a $6.5 \%$ del valor agregado industrial en 1960 . El grupo $\mathrm{C}$ que incluye maquinaria y vehículos de transporte crece lentamente pasando de $2.3 \%$ a $3.4 \%$ en 1950 y 1960 respectivamente. El grupo D que incluye productos quimicos, imprentas y otros, crece significativamente en su participación 
Como podemos apreciar la participación de las distintas agrupaciones de actividades industriales aumenta en relación a la generación del valor agregado industrial. Si bien la agrupación A disminuye su participación, esta crece a una tasa promedio anual de $4.12 \%$ durante el período.

Las ramas más dinámicas son las de papel, caucho, químicos y minerales no metálicos que crecen a una tasa promedio anual superior al $10 \%$ durante los años de la década de los ' 50 .

Las industrias de alimentos, textil, muebles, maquinaria, minerales metálicos, materiales de transporte, imprentas crecen a tasas superiores al $6 \%$ anual. En general todas las ramas industriales presentan tasas de crecimiento significativas, esto nos muestra que al interior del sector industrial ha habido una rápida divercificación productiva, pero que a su vez asumió el carácter sustitutivo de importaciones y desplazó la producción artesanal.

Cuadro No. 14

Evolución de la producción manufacturera por sectores 1950-1960 (Miles de colones de 1962)

\begin{tabular}{|c|c|c|c|c|c|c|c|c|}
\hline \multirow{2}{*}{ Sector de activldades } & \multicolumn{2}{|c|}{ Vilor egregado } & \multirow[b]{2}{*}{1857} & \multirow[b]{2}{*}{1860} & \multicolumn{4}{|c|}{ Tans media enusl de crecimiento \% } \\
\hline & 1050 & 1053 & & & $\begin{array}{l}1950 \\
1953\end{array}$ & $\begin{array}{l}1953 \\
1957\end{array}$ & $\begin{array}{l}1957 \\
1060 \\
\end{array}$ & $\begin{array}{l}1850 \\
1860 \\
\end{array}$ \\
\hline $\begin{array}{l}\text { 1. Alimentes } \\
\text { 2. Bebldas } \\
\text { 3. Tabace } \\
\text { 4. Textiles } \\
\text { 5. Calz. y Vesluario } \\
\text { 6. Madera } \\
\text { 7. Muebles } \\
\text { 8. Cueros }\end{array}$ & $\begin{array}{r}45,155 \\
28,195 \\
9,659 \\
6,520 \\
17,355 \\
1,269 \\
812 \\
1,1,724\end{array}$ & $\begin{array}{r}53,263 \\
27,224 \\
12,145 \\
6,520 \\
21,199 \\
1,379 \\
1,024 \\
1,831\end{array}$ & $\begin{array}{r}6,751 \\
31,871 \\
12,886 \\
9,803 \\
27,199 \\
1,436 \\
1,508 \\
2,021\end{array}$ & $\begin{array}{r}92,860 \\
29,170 \\
12,111 \\
12,221 \\
23,836 \\
1,289 \\
2,047 \\
2,284\end{array}$ & $\begin{array}{r}5,66 \\
-1,16 \\
7,93 \\
11,50 \\
6,94 \\
2,81 \\
8,04 \\
2,03\end{array}$ & $\begin{array}{r}6,97 \\
4,02 \\
1,49 \\
2,05 \\
6,39 \\
1,02 \\
10,06 \\
2,50\end{array}$ & $\begin{array}{r}5,91 \\
-2,91 \\
-2,04 \\
7,63 \\
-4,30 \\
-3,53 \\
10,72 \\
4,16\end{array}$ & $\begin{array}{l}6,25 \\
0,34 \\
2,29 \\
6,48 \\
3,22 \\
0,16 \\
9,69 \\
2,85\end{array}$ \\
\hline A Sub-lolal 1a 8 & 100,689 & 127.134 & 156,475 & 165,621 & 4,73 & $\mathbf{5 , 3 3}$ & 1,95 & 4,12 \\
\hline $\begin{array}{l}\text { 9. Papel } \\
\text { 10. Caucho } \\
\text { 11. Minerales no } \\
\text { metálicos } \\
\text { 12. Minerales } \\
\text { metálicos }\end{array}$ & $\begin{array}{r}110 \\
233 \\
1,441 \\
1,236\end{array}$ & $\begin{array}{r}148 \\
466 \\
3,873 \\
1,013\end{array}$ & $\begin{array}{r}444 \\
995 \\
6,463 \\
1,369\end{array}$ & $\begin{array}{r}429 \\
1,198 \\
0.585 \\
2,747\end{array}$ & $\begin{array}{r}10,40 \\
25,99 \\
38,67 \\
-6,42 \\
\end{array}$ & $\begin{array}{r}31,60 \\
20,88 \\
13,66 \\
7,82 \\
\end{array}$ & $\begin{array}{r}-1,14 \\
6,39 \\
9,93 \\
26,13\end{array}$ & $\begin{array}{r}14,58 \\
17,79 \\
19,54 \\
8,31\end{array}$ \\
\hline B. Sub-tdal 9 a 12 & 3,020 & 5,500 & 9,271 & 12,959 & 22,12 & 13,94 & 11,81 & 15,68 \\
\hline $\begin{array}{l}\text { 13. Maquinaria } \\
\text { 14. MaL de Transporte }\end{array}$ & $\begin{array}{r}975 \\
1,842 \\
\end{array}$ & $\begin{array}{l}1,172 \\
2,251 \\
\end{array}$ & $\begin{array}{l}2,322 \\
3,511 \\
\end{array}$ & $\begin{array}{l}2,217 \\
4,606 \\
\end{array}$ & $\begin{array}{l}6,33 \\
6,91 \\
\end{array}$ & $\begin{array}{l}18,64 \\
11,75 \\
\end{array}$ & $\begin{array}{r}-1,53 \\
9,47 \\
\end{array}$ & $\begin{array}{l}8,56 \\
9,60 \\
\end{array}$ \\
\hline C. Sub-Idal 13a 14 & 2,817 & 3,423 & 5,833 & 6.823 & 6.71 & 14,25 & 5,36 & 9,25 \\
\hline $\begin{array}{l}\text { 15. Producas } \\
\text { Qulmicas } \\
\text { 16. Imprenlas } \\
\text { 17. Oiros }\end{array}$ & $\begin{array}{l}2,438 \\
1,879 \\
1,528 \\
\end{array}$ & $\begin{array}{l}3,988 \\
2,391 \\
1,906 \\
\end{array}$ & $\begin{array}{l}5,273 \\
3,191 \\
2,447 \\
\end{array}$ & $\begin{array}{l}6,770 \\
3,791 \\
\mathbf{4 , 3 8 2} \\
\end{array}$ & $\begin{array}{r}17,62 \\
7,30 \\
7,65 \\
\end{array}$ & $\begin{array}{l}7,23 \\
6,28 \\
6,45 \\
\end{array}$ & $\begin{array}{r}8,68 \\
5,91 \\
21,43 \\
\end{array}$ & $\begin{array}{r}10,75 \\
7,27 \\
11,11 \\
\end{array}$ \\
\hline D. Sub-ldal 15 a 17 & 5,845 & 8,215 & 10,911 & 14,943 & 12,01 & 7,35 & 11.05 & 9,84 \\
\hline E. Tolal & 122,371 & 144,272 & 182,480 & 200,546 & 5,64 & 6,05 & 3,19 & 5,06 \\
\hline
\end{tabular}

Fuente: Elaborado en base a datos de CONAPLAN. Indicadores Económicos y Sociales. San Salvador. Septiembre-Diciembre 1971.

Nota: Los sub-totales A, B. C y D, corresponden a las agrupaciones que CONAPLAN llama "industrias tradicionales," "industrias intermedias," "industrias mecánicas," "industrias diversas" (ver, por ejemplo, el Plan de la Nación para el Desarrollo Económico y Social 1965-1969). 
crecimiento significativas, esto nos muestra que al interior del sector industrial ha habido una rápida diversificación productiva, pero a su vez asumió el caracter sustitutivo de importaciones y desplazó la producción artesanal.

"La sustitución de la producción artesanal se realizan a causa de las inversiones en la producción de bienes de consumo no duraderos (textiles, calzado, jabones, esencialmente) en los que ese tipo de taller acumula los tres cuartos de las personas ocupadas en la producción". ${ }^{38}$

Al respecto de la sustitución de importaciones se dice que "a pesar del crecimiento de todos los sectores y de las inversiones de innovación que sustituyen importaciones de bienes no producidos antes en El Salvador, no podemos hablar de un serio proceso de sustitución de importaciones en el país, primordialmente en lo que a bienes de consumo se refiere". 39

Cuadro No. 15

Estructura de la disposición Interna de manufacturas por origen y destino: 1951-1956-1962

\begin{tabular}{|l|c|c|c|}
\hline & 1951 & 1956 & 1962 \\
\hline $\begin{array}{l}\text { 1. Bienes de consumo } \\
\text { a) Nacional }\end{array}$ & 75,4 & & \\
b) Importado & 24,3 & 25,1 & 79,7 \\
2. Materias primas & & & 20,3 \\
a) Nacional & 42,3 & 40,8 & 50,0 \\
b) Importado & 87,9 & 59,2 & 50,0 \\
3. Bienes de capital & & & \\
a) Nacional & 12,1 & 11,2 & 22,6 \\
b) Importado & 87,9 & 88,8 & 77,4 \\
4. Total & & & \\
a) Nacional & 61,6 & 60,8 & 67,1 \\
b) Importado & 38,4 & 39,2 & 32,9 \\
\hline
\end{tabular}

Fuente: CONAPLAN, Plan de la Nación para el desarrollo económico y social 1965-1969, Segunda parte, Vol. 2 Pág. 112. Tomado de Dada Héctor. Op. Cit. Pág. 60.

La estructura industrial de El Salvador se habia diversificado, el proceso de sustitución de importaciones se presentaba en algunas ramas específicas, pero no asume un alto grado sustitutivo como evidencia el cuadro No. 15, más la expansión y diversificación industrial había incidido negativamente en la producción artesanal manufacturera provocando 
la contracción de estas actividades.

La estructura industrial evidencia a su vez debilidades ya que "no produce casi ningún bien de equipo y cuyos bienes intermedios están dedicados o al desarrollo urbano impulsado por la burguesía agro-exportadora o a ser insumos de la misma producción agricola. La producción de bienes duraderos es reducida a manufacturas ligeras". 40

Esta última afirmación evidencia en si el carácter de la industrialización en El Salvador, concentrada en la producción de bienes no duraderos y esencialmente, una industria ligera y adecuada a las necesidades del modelo agro-exportador.

Otro de los aspectos significativos de la industria es su carácter concentrador: "las empresas que utilizan más de 100 personas -personal administrativo incluido - no llegan a ser ni el $1 \%$ del total, pero ocupan más de la cuarta parte del personal ocupado, participan en más del 55\% de la producción bruta total y producen la mitad de todo el valor agregado del sector". 41

"En el otro extremo las empresas de menos de 10 personas representan casi el $92 \%$ de las empresas industriales y ocupan el $45 \%$ de la fuerza de trabajo, mientras sólo producen el $14 \%$ de la producción bruta y casi el $21 \%$ del valor agregado". ${ }^{42}$

En general podriamos sefialar que la industria cobra importancia a nivel de la economía, el carácter sustitutivo de importaciones no se manifiesta tan plenamente en esta estructura industrial, pero su dinámica es creciente en el periodo. Esta industria presenta debilidades en el marco de su orientación y articulación externa, a su vez su dinámica concentradora entra en contradicción con los requerimientos de una expansión del mercado interno donde encontrará serios limites a su crecimiento futuro.

"Según constata la CEPAL, entre 1951 y 1957 el empleo industrial crece a una tasa de $2.7 \%$ esta es menor que la tasa de crecimiento de la población (3\%) y menor aún que el propio crecimiento del sector $(5.1 \%)$. Por su lado CONAPLAN afirma que entre 1951 y 1961 el empleo industrial (exceptuando el beneficio del café) crece en una tasa menor de $2.7 \%$. Esto se da junto a una progresiva sustitución del trabajo artesanal". ${ }^{43}$

Los salarios durante el periodo no parecen haber aumentado sustancialmente, el salario promedio anual de un obrero esta alrededor de los 651 colones, esto significa deficiencias en relación a la expansión del mercado interno, aspecto necesario al proceso de industrialización más sostenido. La concentración del ingreso se mantiene al final de la década casi igual que a sus inicios, problema que obligará a la busqueda de alternativas en el mercado regional integrado.

Por último cabe mencionar que la acción estatal, implicita o explícita- 
mente fomentó la inversión extranjera directa, las cuales se veran favorecidas por los mismos mecanismos que estimularon la inversión nacional, tal es asi que la inversión extranjera directa en la industria de Transformación de El Salvador pasa de 6.2 millones de colones en 1953 a 25.7 millones de colones en 1960.

A manera de conclusión de este apartado podemos decir, que la acción del Estado como promotor del crecimiento industrial propició la expansión de esta actividad en el período de 1948-1960, la estructura productiva global como industrial se diversifico relativamente, asi hubo un relativo proceso de sustitución de importaciones a través de la industria manufacturera. Los limites de la acción estatal a fin de promover la industrialización se encuentran en el carácter que adopta y tiene el aparato productivo, su carácter concentrador y articulado al exterior son el freno real a una mayor efectividad de la acción estatal es este campo. Es decir el límite a la efectividad mayor de la politica estatal a fines de la década es "estructural".

\subsection{Efectividad de la administración pública}

La efectividad de la política gubernamental, la podemos apreciar a través del grado de intervención del Estado en la economia y el nivel del gas-

Cuadro No. 16

Grado de intervención del Estado en la economía y grado de gasto de fomento económico-social

\begin{tabular}{|c|c|c|c|c|c|}
\hline Año & P.T. B. & $\begin{array}{c}\text { Gaslo tolal } \\
\text { goblerno }\end{array}$ & $\begin{array}{c}\text { Gasto de } \\
\text { fomento }\end{array}$ & $\begin{array}{c}\text { Grado de } \\
\text { Intervenclón } 1\end{array}$ & $\begin{array}{c}\text { Grado de } \\
\text { fomento } 2\end{array}$ \\
\hline 1950 & 903.2 & 88.7 & 42.2 & 9.8 & 47.5 \\
1951 & 956.8 & 121.4 & 58.9 & 12.7 & 48.5 \\
1952 & $1,018.0$ & 131.2 & 61.6 & 12.9 & 46.9 \\
1953 & $1,044.8$ & 124.1 & 65.2 & 11.9 & 52.5 \\
1954 & $1,077.7$ & 142.4 & 85.5 & 13.2 & 60.0 \\
1955 & $1,124.1$ & 146.3 & 78.6 & 13.0 & 53.7 \\
1956 & $1,191.7$ & 154.8 & 79.0 & 13.0 & 51.0 \\
1957 & $1,258.8$ & 170.2 & $76.4^{*}$ & 13.5 & 44.9 \\
1958 & $1,271.8$ & 179.8 & & 14.1 & \\
1959 & $1,328.9$ & 181.5 & $70.0^{*}$ & 13.7 & 38.6 \\
1960 & $1,382.7$ & 168.4 & & 12.1 & \\
\hline Promedio & & & & 12.7 & 49.3 \\
$1950-1960$ & & & & & \\
\hline
\end{tabular}

Fuente: Banco Central de Reserva de El Salvador. Op. Cit. y Estadisticas del Ministerio de Hacienda.

1 Grado de intervención del Estado en la economla gasto total del gobierno entre el PTB.

2 Grado de fomento: gasto de tomento entre gasto total del gobierno.

- Dalos estimados 
to de fomento en relación al gasto total. Estos dos indicadores podrian evidenciar por un lado la creciente acción del Estado en la economia y la orientación fundamental de su gasto, a su política deliberada de fomento económico-social en función de la industrialización.

Según los indicadores del cuadro No. 16 podemos apreciar que la intervención del Estado en la economia ha crecido de $9.8 \%$ en 1950 a $14.1 \%$ en 1958, manteniéndose un promedio anual de $12.7 \%$, este significativo crecimiento de la acción estatal en la economía obedece al interés del Estado de promover el desarrollo industrial y la modernización de la economía.

El grado de fomento económico social es importante ya que en promedio durante el período el Estado orienta cerca del $50 \%$ de su gasto a obras de infraestructura, educación, salud y seguridad social, con lo que garantiza tanto la dinámica de acumulación como el bienestar de la población necesaria a la mantención de la relativa estabilidad política. (ver cuadro No. 17).

Las inversiones públicas entre 1950 y 1956 crecen a una tasa promedio anual de $26.7 \%$, mientras que la inversión privada lo hace a un $14.6 \%$, a su vez este ritmo de crecimiento de la inversión pública es superior al incremento promedio de la inversión bruta nacional que alcanza el 15.4\%; esto refleja la importancia de la acción del Estado en la actividad económica en este período. (Ver cuadro No. 18).

Otra forma de percibir la importancia de la acción estatal en la economía podría ser a través de una de las medidas de mayor impacto económico como es la Ley de Fomento de Industrias de Transformación; desde la vigencia de esta Ley en 1952, el número de empresas que se acogen a esta Ley llega a alcanzar 221 en 1960 y la inversión proyectada acumulada durante este período es de 186.3 millones de colones. Aspectos significativo del carácter promotor y benefactor del Estado hacia la actividad industrial.

La mayor intervención del Estado en la economia, la orientación del gasto a la acumulación de capital y al bienestar social, los importantes incentivos fiscales y financieros, y la inversión creciente del sector público muestran el interés del Estado a una acción más efectiva para el logro de los objetivos planteados en su proyecto político-económico de modernización e industrialización.

La estructura del aparato administrativo del Estado, que tiene la funcionalidad de desarrollar las distintas acciones de este en sus distintos campos, ya sea como regulador, acumulador y legitimador de su proyecto; presenta a partir de 1950 cambios importantes.

El aparato estatal se redefine a partir de 1950 para adecuarse a las ne- 
cesidades del proyecto político-económico modernizante y promotor de la industrialización. Las exigencias del nuevo proceso hacen que el aparato estatal se divida en dos grandes sectores el tradicional y el moderno, el primero dedicado a las tareas administrativas y organizativas tradicionales, mientras el segundo en función del proceso de desarrollo modemizante.

\section{Cuadro No.17}

Gastos de fomento por destino: 1950-1956 (Millones de colones)

\begin{tabular}{|c|c|c|c|c|c|c|c|}
\hline Año & $\begin{array}{c}\text { Obras puilleas } \\
\text { y fomento } \\
\text { Econom. }\end{array}$ & $\begin{array}{c}\text { \% del tolal } \\
\text { gastos }\end{array}$ & $\begin{array}{c}\text { Salud, } \\
\text { educaclón y } \\
\text { blenestar } \\
\text { soclal }\end{array}$ & $\begin{array}{c}\text { \% del tolal de } \\
\text { gaslos }\end{array}$ & $\begin{array}{c}\text { Pensióny } \\
\text { seguridad } \\
\text { soclal }\end{array}$ & \% & Total \\
\hline & 19.6 & 22.1 & 20.2 & 22.8 & 2.4 & 2.7 & 42.2 \\
1950 & 29.0 & 23.9 & 27.1 & 22.3 & 2.8 & 2.3 & 58.9 \\
1951 & 22.3 & 17.4 & 30.2 & 23.6 & 9.1 & 7.1 & 61.6 \\
1952 & 24.1 & 17.7 & 30.7 & 22.6 & 10.4 & 7.6 & 752 \\
1953 & 29.7 & 19.3 & 44.2 & 28.4 & 11.6 & 7.5 & 85.5 \\
1954 & 29.8 & 19.4 & 36.1 & 23.5 & 12.7 & 8.3 & 78.6 \\
1955 & 28.4 & 18.6 & 37.5 & 24.5 & 13.1 & 8.6 & 79.0 \\
1956 & 28 & &
\end{tabular}

Fuente: BIRF Situación Actual y Perspectiva de la Economía de El Salvador 1958. Publicación del Ministerio de Economla.

* Porcentajes en relación al total del gasto del gobierno.

Cuadro No. 18

Estimaciones de las Inverslones brutas nacionales 1950-1956 Millones de colones

\begin{tabular}{|c|c|c|c|c|c|c|}
\hline Afio & $\begin{array}{c}\text { Inversiones } \\
\text { privadas }\end{array}$ & $\%$ & $\begin{array}{c}\text { Inversiones } \\
\text { públicas }\end{array}$ & $\%$ & $\begin{array}{l}\text { Inversión } \\
\text { bruta Nac }\end{array}$ & $\%$ \\
\hline & 135.3 & & 23.0 & & 158.3 & \\
1950 & 164.8 & 21.8 & 44.4 & 93.0 & 209.2 & 32.0 \\
1951 & 174.0 & 5.6 & 48.6 & 9.5 & 222.6 & 6.4 \\
1952 & 185.0 & 6.8 & 58.4 & 20.2 & 244.2 & 9.7 \\
1953 & 219.0 & 17.9 & 64.9 & 11.1 & 283.9 & 16.3 \\
1954 & 251.2 & 14.7 & 69.5 & 7.1 & 320.7 & 13.0 \\
1955 & 285.8 & 13.8 & 82.7 & 19.0 & 368.5 & 14.9 \\
1956 & & 14.6 & & 26.7 & & 15.4 \\
\hline Promedio & & & & & & \\
1950-1956 & & & & & & \\
\hline
\end{tabular}

Fuente: BIRF. Ibid. 
Cuadro No. 19

Personal burocrático 1948-1962

\begin{tabular}{|c|c|c|}
\hline Ano & Sector tradicional & Sector moderno \\
\hline & & - \\
1948 & 18,835 & - \\
1952 & 16,611 & 1,158 \\
1954 & 21,956 & 1,158 \\
1956 & 30,003 & 1,340 \\
1958 & 23,930 & 5,487 \\
1962 & 44,488 & \\
\hline
\end{tabular}

Fuente: En base a datos de Evolución Histórica de el Sector Público en El Salvador. Investigación ULA-ICAP-Fundación FORD. San Salvador, 1980.

El sector tradicional "agrupa a todos los Ministerios del aparato estatal que prestan servicios públicos vinculados a la producción y exportación de los productos agricolas del modelo de desarrollo hacia afuera y los que legitiman y garantizan la vigencia del Estado". 44

A su vez este sector se subdivide en: a) sector de desarrollo de recursos naturales; b) sector de desarrollo social; c) sector de desarrollo de la infraestructura; d) sector de desarrollo de la producción; e) sector de servicios económicos y financieros; f) sector de administración y servicios generales.

Este sector tradicional crece en términos de personal, dado no solamente los requerimientos de la acción tradicional del Estado sino que debe apoyar las acciones que posibiliten la acumulación en otras actividades económicas como la industria. Asi el personal aumenta en más de 2.3 veces entre 1948 y 1962, pasando de 18,835 a 44,488 en los respectivos años.

"El sector moderno del aparato estatal agrupa a las instituciones autónomas, las que crean condiciones básicas que tacilitan la industrialización". ${ }^{5}$ En este sector el personal crece también en forma importante habiendo aumentado casi 5 veces entre 1952 y 1962, de 1,158 personas a 5,487 personas respectivamente.

Como señalabamos en acápites anteriores el Estado establece un conjunto de acciones en el marco de la acumulación y la búsqueda del concenso social que permiten el desarrollo de su proyecto, en este sentido podemos señalar que las áreas del aparato estatal que se dedican a la función de acumulación son los sectores (definidos en instituciones) dedicados a recursos naturales, infraestructura, producción, servicios económicos y financieros. 
Mientras que por el lado del concenso social se utilizaran todas aquellas instituciones del sector social (a través del bienestar), la administración y servicios generales dentro del cual se ubican los poderes públicos, el ramo de defensa, del interior, relaciones exteriores y los cuerpos de seguridad; que garantizaran la legitimidad del Estado y el concenso social a través de mecanismos de beneficio social o de carácter cohercitivo.

El sector moderno del aparato estatal, formada por instituciones autónomas se adecua más propiamente a las necesidades modernizantes de la economía, entre estas se puede mencionar a la Comisión Ejecutiva $\mathrm{Hi}$ droeléctrica del Río Lempa (CEL, 1945), el Centro Nacional de Productividad (CENAP, 1952), Comisión Ejecutiva Portuaria Autónoma (CEPA, 1952), Instituto de Vivienda Umana (IVU, 1950), Instituto Salvadoreño del Seguro Social (ISSS, 1949), Instituto Regulador de Abastecimientos (IRA, 1950), Instituto Salvadoreño de Fomento de la Producción (INSAFOP, 1955), etc.

Todas estas instituciones cumplen un rol importante desde la necesidad del proceso de acumulación de capital y el crecimiento económico que el Estado habia proyectado deliberadamente.

\section{Conclusiones}

Se trata de evidenciar en que forma el Estado durante el período de 1948 a 1960, se redefine en función de un proyecto político-económico, promueve la acumulación de capital a través de la industrialización y en general la modernización de la economía salvadorefia.

El Estado que surge a partir de 1948 establece un Proyecto PolíticoEconómico, que responde a las nuevas exigencias del desarrollo del capitalismo mundial y al interés de los grupos económicos sociales internos que perciben posibilidades de realización de su capital a través de la industrialización, estos grupos económicos a su vez no esta desvinculados de las actividades de agro-exportación, ya que seran estos los que inviertan en las actividades promovidas por Estado.

El Estado en este periodo a través de su acción acumuladora y reguladora desarrolla una serie de medidas que fomentan, incentivan y estimulan la inversión privada en la actividad industrial; pero así mismo establece un conjunto de medidas orientadas a lograr el relativo concenso social y bienestar de la población; a fin de legitimar su proyecto político-económico. Se crean asi una serie de leyes de fomento económico, surgen nuevas instituciones públicas, se legisla en el área social, se orienta el gasto público en función de crear las condiciones económicas y sociales que garanticen el desarrollo de este proyecto. 
Es importante tambien señalar que el Estado utiliza una serie de mecanismos político-ideológicos y cohercitivos para lograr una relativa estabilidad política-social que permite a su vez la expansión de la inversión privada en la industria.

Para poder comprender mejor que la redifinición del Estado fué acorde a las necesidades del proyecto político-económico que impulsó, se trato de medir la efectividad de las medidas desarrolladas durante el periodo de 1948 a 1960; en este sentido el mayor grado de intervención del Estado en la economia establecida a través de su mayor nivel de gasto público y de gasto en infraestructura, fomento económico y social; permitió apreciar que el grado industrialización de la economia fuera creciente y que se presentara una relativa diversificación de la economia especialmente en la estructura productiva industrial.

Asímismo el crecimiento del aparato administrativo del Estado en relación al surgimiento de nuevas instituciones y al crecimiento del personal burocrátivo fué una respuesta acorde a las necesidades que la lógica de acumulación exigian.

En general la redifinición del Estado ,así como la efectividad de los mecanismos utilizados para desarrollar sus acciones de acumulación, regulación y legitimación, permitieron desarrollar el proyecto político económico de carácter industrializante durante el período de 1948-60. Pero a fines de la década de los '50, el Estado encuentra los límites a su propia acción debido a la presencia de factores estructurales que evidenciaran las debilidades de un modelo económico: que estimuló la concentración económica, no posibilitó la expansión del mercado interno, que propició una estructura industrial fuertemente dependiente del mercado extemo y debil en cuanto a la sustitución de importaciones, así también no logro generar las condiciones de un desarrollo más autónomo y equitativo.

\section{Notas}

1. Dada, Héctor. La Economla de El Salvador y la Integración Centroamericana 19451960. UCA Editores. Págs. 37-38.

2. Guidos Vejar, José Ralael. El Papel del Estado en el Proceso de Industrialización en El Salvador. Documento Mimeografiado. 1974. Pág.40.

3. Ibid. Pág. 19.

4. Op. Cit. Dada. Héctor. Pág. 39.

5. Op. Cit. Guidos V., J. Rafael. Pág. 31.

6. Ibid. Pág. 32.

7. La Producción algodonera presentaba, a decir de varios autores entre ellos Emesto Fichter, características más avanzadas que la producción cafetalera, el mayor grado de mecanización en las distintas fases de producción, asl como la alta rentabilidad del cultivo cuya producción se habla orientado en forma creciente al mercado externo y a satisfacer las necesidades de una industria lextil en expansión. permitla volver atractiva la inversión en la industria para los grupos agro-exportadores y que de éste modo pusiera menos resistencia a los cambios de la politica económica iniciados en 
1948. Ver Richter, Emesto. El proceso de acumulación en la formación económicasocial salvadoreña. Mimeo. Dada, Héctor. Op. Cit. Pág. 34.

8. Op. Cit. Dada, Héctor. Pág. 41.

9. El caracterizar el comportamiento tradicional de los grupos agro-exportadores es importante para percibir si estos sectores podrían o no, ser receptivos a nuevas medidas que promuevan la reorientación de su capital en actividades si bien rentables pero con mayor riesgo y un perlodo más largo de recuperación de sus inversiones. Ver Guidos, Rafael Op. Cit. Págs. 37-38.

10. Op. Cit. Dada, Héctor. Pág. 43.

11. Ibid. Pág. 44.

12. Op. Cit. Guidos V. Rafael. Pág. 60.

13. Constitución Pollitica 1950 citado en Guidos Vejar, Ralael. Ibid. Pág. 63.

14. Ibid. Pág. 64.

15. Esto quiere decir que en un perlodo relativamente corto 1949 a 1953 la Fábrica de Cemento habla logrado un alto nivel de rentabilidad y por lo tanto beneficios para sus accionistas.

16. Op. Cit. Guidos Vejar, Rafael. Pág. 62.

17. Ibid. Pág. 62.

18. Ibid. Pág. 66.

19. Ibid. Pág. 66.

20. La Ley de Vialidad si bien era un gravamen al capital, no pretendla desestimular la inversión, ni obtener a través de estos impuestos los ingresos para que el Estado desarrolle su acción de creación de infraestructura. Este impuesto llegaba a constituir alrededor de $1.8 \%$ de los ingresos tributarios del gobierno en 1954. Ver Guidos, Rafael. Pág. 66.

21. Op. Cit. Dada, Héctor. Pág. 55.

22. CONAPLAN, Diagnóstico del Sector industrial 1950-62, El Salvador. Pág. 193. Tomado de Goitia, Allonso. La Politica Estatal a la Inversión Extranjera Directa en el Sector Industrial de El Salvador 1950-1960. Tesis UCA, 1981.

23. Ibid. Pág. 55.

24. INSAFOP. Memoria de Labores 1956. Pág. 7.

25. lbid. Pág. 7.

26. Op. Cit. Dada, Héctor. Pág. 54.

27. Op. Cit. Guidos, Ralael. Pág. 18.

28. Op. Cit. Dada, Héctor. Pág. 54.

29. Op. Cit. Guidos, Rafael. Pág. 55.

30. Ibid. Pág. 55.

31. Menjlvar, Rafael. Formación y Lucha del Proletariado Industrial Salvadoreño. UCA Editores 1979. El Salvador. Pág. 91.

32. Op. Cit. Guidos, Rafael. Pág. 71.

33. Ibid. Pág. 71.

34. Lungo, Mario. El Salvador, 1932-1978. La Crisis del Estado y el Papel de las Políticas Sociales (acerca de las funciones que cumplen las pollticas de vivienda). Mimeo, 1978. Pág. 7.

35. Op. Cit. Menjivar, Rabael. Pág. 91.

36. Ibid. Pág. 91.

37. Ibid. Pág. 93.

38. Op. Cit. Dada, Héctor. Pág. 56.

39. Ibid. Pág. 58.

40. Ibid. Págs. 71-73.

41. Ibid. Pág. 66.

42. Ibid. Pág. 66-67.

43. Ibid. Pág. 77. 
44. Investigación UCA-ICAP-FUNDACION FORD. Evaluación Histórica del Sector Público en El Salvador. Proyecto: Evolución Histórica del Sector Público en Centroamérica y Panamá. San Salvador Agoslo 1980. Págs, 87-88.

45. Ibid. Pág. 105. 